\title{
Introduction to the First International Workshop on Services, Energy, and Ecosystem (SEE 2010)
}

\author{
Barbara Pernici ${ }^{1}$, Schahram Dustdar ${ }^{2}$, G.R. Gangadharan ${ }^{1}$, \\ Patricia Lago ${ }^{3}$, and San Murugesan ${ }^{4}$ \\ 1 Politecnico di Milano, Italy \\ barbara.pernici@polimi.it, geeyaar@gmail.com \\ 2 Technical University of Vienna, Austria \\ 3 VU University Amsterdam, Netherlands \\ patricia@cs.vu.nl \\ 4 University of Western Sydney, Australia \\ san1@internode.net
}

\begin{abstract}
The first international workshop on Services, Energy, and Ecosystem (SEE 2010) focused on creating sustainable (green) energyefficient services and fostering the growth towards a new eco-friendly world of services. Technical papers of high quality have been submitted, of which six were accepted (with a $60 \%$ of acceptance rate). Moreover, a keynote given by Professor Barbara Pernici presented an overview on research projects funded by the European Commission toward energy efficiency in ICT.
\end{abstract}

Keywords: green IT, energy efficiency, services.

\section{Aims and Scope}

Although significant progress has been made in the recent years in making computing greener, i.e. energy-efficient and environmentally sustainable, the net impact of improvements in energy efficiency is generally more than offset by increasing demand for computing power and capacity, driven by new digitized business processes and services. The total energy consumption has been increasing due to proliferation of computers, data centers and various types of mobile computing and communication devices, as well as by the emergence of, and demand for, new applications. To address this issue holistically, there is now call for making applications and services themselves energy-aware and -efficient. New innovative ICT-based tools for monitoring and managing energy consumption in several application have emerged, and novel approaches for creating energy-aware systems and applications are being developed to create a better and sustainable ecosystem.

The SEE workshop solicited research submissions and real-world experiences on all topics related to Services, Energy, and Ecosystems, to bring together 
researchers and practitioners from multidisciplinary fields working on energyaware and energy-efficient systems and applications and to set an agenda for further work in this important new area. In particular the following topics have been presented and discussed:

1. Engineering Energy-Efficient Systems, Applications and Services;

2. Monitoring and Managing Energy-Aware Services;

3. Fostering Ecosystems in Organizations and Society.

\section{Workshop Co-organizers}

- Prof. Barbara Pernici (Politecnico di Milano, Italy)

- Prof. Schahram Dustdar (Technical University of Vienna, Austria)

- Dr. G.R. Gangadharan, Politecnico di Milano, Italy)

- Prof. Patricia Lago, VU University Amsterdam, Netherlands)

- Prof. San Murugesan (University of Western Sydney, Australia)

\section{Programm Committee}

- Rami Bahsoon University of Birmingham, UK

- Ivona Brandic, Technical Univ. of Vienna, Austria

- Jon Crowcroft, Cambridge University, UK

- Mariagrazia Fugini, Politecnico di Milano, Italy

- Aditya Ghose, University of Wollongong, Australia

- Ronen Kat, IBM Haifa, Israel

- Alexander Kipp, University of Stuttgart, Germany

- Dana Petcu, West University of Timisoara, Romania

- Pierluigi Plebani, Politecnico di Milano, Italy

- Ioan Salomie, Tech. Univ. of Cluj-Napoca, Romania

- Thomas Setzer, Tech. Univ. of Mnchen, Germany

- Bhuvan Unhelkar, MethodScience, Australia

\section{Additional Reviewers}

- Ivan Breskovic 